\title{
Computational Study of the Molecular Structure, Vibrational Spectra and Energetics of the OIO Cation
}

\author{
Sang Yeon Lee \\ Department of Applied Chemistry, Kyungpook National Chiversin, Daegu 702-701. Korea \\ Received October,+ 2004
}

\begin{abstract}
Molecular geometries for the cationic and neutral species of $\mathrm{OXO}(\mathrm{X}=\mathrm{Cl}$. $\mathrm{Br}$. and $\mathrm{I})$ are optinized using the Hartree-Fock (HF) theory. the second order Moller-Plesset perturbation theory (MP2), the density functional theory with the B3LYP hybrid functional (B3LYP). and the coupled cluster theory using single and double excitation with a perturbational treatment of triplet excitation ( $\operatorname{CCSD}[T])$ methods, with two basis sets of triple zeta plus polarization quality. The single point calculations for these species are performed at the CCSD(T.Full) level. The harmonic vibrational frequencies for these species are calculated at the HF. MP2. B3LYP and $\operatorname{CCSD}(\mathrm{T})$ levels. The adiabatic ionization potential for $\mathrm{OIO}$ is calculated to be $936.7 \mathrm{~kJ} / \mathrm{mol}$ at the $\operatorname{CCSD}$ (T,Full) level and the correct value is estimated to be around $945.4 \mathrm{~kJ} / \mathrm{mol}$.
\end{abstract}

Key Words : Halogen dioxides. Ionization potential, Vibrational frequency. $A b$ initio MO calculation

\section{Introduction}

Although iodine oxides have been known for more than 100 years. their chemistry has not been received much

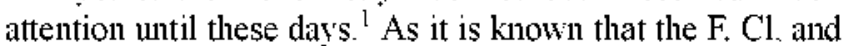
$\mathrm{Br}$ atoms and their oxides play an important role in the ozone depletion in the stratosphere and that the efficiency of the heavier halogen atoms in the ozone depletion has been estimated to be larger than that of the lighter halogen atoms. " the role of iodine and iodine oxides in the atmosphere is interesting because they are expected to be more effective in the ozone decomposition. The investigation of iodine chemistry in the atmosphere discovers that iodine species are implicated in the ozone decomposition in the troposphere and lower stratosphere and they are involved in aerosol formation in the marine boundary layer. ${ }^{3-5}$ Although many experiments and theoretical studies have been performed in order to understand iodine chemistry in the atmosphere. chemical and physical data for iodine oxides are very scarce. Among the iodine oxides known to be involved in the atmospheric processes. only $\mathrm{OI}$ is well characterized

The next simplest iodine oxide. OIO. is known to be involved in the ozone depletion and is considered to serve as the starting point for the formation of iodine aerosols in the marine boundary layer ${ }^{3-5}$ Miller and Cohen reported the molecular structure of $\mathrm{OIO}$ in the ground state derived from its rotational spectrum. ${ }^{6}$ The vibrational frequencies for the ground state of OIO have been reported from the vibrational spectra for species in the matrix isolation experiment. the photoelectron spectra of the $\mathrm{OIO}$ anion and the absorption spectra of OIO ${ }^{7-9}$ Himmelmann $e t a l$ and Ashworth et $a l$. have reported the absorption spectrum of OIO in the ground state. ${ }^{9.15}$ There. however. is no direct experimental determination of the enthalpy of formation for OIO except the upper

"e-mail: sanglee $\bar{c}$ knuluckr limit. $\Delta_{H} H_{298}^{o}<135 \mathrm{~kJ} / \mathrm{mol}$ which was derived by Bedjanian et $a l^{11}$ The photoionization mass spectroscopic method has been successfully applied in determining the enthalpies of formation for simple molecules such as $\mathrm{OBrO}{ }^{12}$ Before this technique can be employed in studies determining the energetic properties of OIO knowledge of the adiabatic ionization potential would be useful.

In this work, the Hartree-Fock theory, the second order Moller-Plesset perturbation theory the density functional theory with the B3LYP hybrid functional, and the coupled cluster theory using single and double excitation with a perturbational treatment of triplet excitation methods are employed to calculate the adiabatic ionization potential for OIO.

\section{Calculations}

All calculations were performed with the Gaussian 98 program suite. ${ }^{13}$ Molecular structures of the neutral and cation species of $\mathrm{OXO}(\mathrm{X}=\mathrm{Cl} . \mathrm{Br}$, and $\mathrm{I})$ are optimized using the Hartree-Fock theory the second order Moller-Plesset perturbation theory, the density functional theory with the B3LYP hybrid functional, and the coupled cluster theory using single and double excitation with a perturbational treatment of triplet excitation methods. The single point energy calculations were performed at the CCSD(T.Full) level at the geometries optimized with the $\operatorname{CCSD}(\mathrm{T})$ method to account for the effects of core-valence correlation. All calculations were performed using two different basis sets of triple-zeta plus polarization quality or better. The first set is $6-311+G(3 \mathrm{df})$ for all atoms. ${ }^{14.15}$ This basis set is denoted as $\mathrm{AE}$ because all electrons are treated in the calculations explicitly. The second set utilizes the 7 valence electron relativistic effective core potentials developed by Christiansen et al. for $\mathrm{Br}$ and $\mathrm{I}$ atoms. ${ }^{16}$ The associated basis functions for $\mathrm{Br}$ and $\mathrm{I}$ atom developed by Lee were used. ${ }^{17}$ The basis functions for $\mathrm{Br}$ and $\mathrm{I}$ atom were consisted of the ( $7 \mathrm{~s} 7 \mathrm{p} 3 \mathrm{~d} 2 \mathrm{f}$ ) 
primitive Gaussian functions and were contracted to the (4s $4 \mathrm{p} 3 \mathrm{~d} 2 \mathrm{f}$ ) set. For other atoms except for $\mathrm{Br}$ and I atom, the $6-311+G(3 \mathrm{df})$ basis set were employed. This basis set is denoted as ECP to indicate that only the valence electrons for the $\mathrm{Br}$ and $\mathrm{I}$ atoms are treated explicitly:

The total energy for each molecular species was corrected by the zero-point vibrational energy (ZPVE). For diatomic molecules. ZPVE $=\left(\omega_{\varepsilon} / 2\right)-\left(\omega_{\varepsilon} \chi_{\varepsilon} / 4\right)$. For polyatomic molecules. ZPVE $=1 / 2 \sum_{i} \omega_{i}+1 / 4 \sum_{i \Sigma_{j}} \chi_{i j}$. When experimental vibrational frequencies are not available. the harmonic vibrational frequencies calculated at the level of B3LYP/AE are used.

\section{Results and Discussion}

The optimized molecular structures for the cationic and neutral species of OIO are listed in Table 1. The experimental equilibrium geometry of $\mathrm{OlO}$ is included for comparison. ${ }^{6}$ Miller and Cohen recorded the rotational spectra of OIO and derived the $r_{i j}$ structure from the spectra which is used to estimate the equilibrium stnucture. $r_{e}$.

The $\mathrm{OIO}$ in the ground state has $\mathrm{C}_{3}$ symmetry. The I-O bond length of OIO optimized at the HF/AE level is smaller than the experimental value by $0.042 \mathrm{~A}$ but the O-I-O bond angle deviates only $-0.7^{\circ}$ from the experimental value. As the calculation method is changed to better methods such as MP2, B3LYP $\operatorname{CCSD}(\mathrm{T})$, the optimized I-O bond length increases by $0.052-0.062 \mathrm{~A}$. so that the agreements between the calculated and experimental values improve significant1y: The deviations of the bond length from the experimental value are 0.010.0.018. and 0.016 A for MP2. B3LYP and $\operatorname{CCSD}(\mathrm{T})$. respectively. The HF method underestimates the bond length by $0.042 \mathrm{~A}$ but all other methods overestimate the bond length by more than $0.01 \AA$.

As the AE basis is changed to the ECP basis. the optimized I-O bond length decreases by $0.013-0.020 \mathrm{~A}$. so that the agreements between the calculated and experimental values improve significantly. The O-I-O angle however. shows

Table 1. The Optimized and Experimental Molecular Structures ${ }^{2}$ of $\mathrm{OIO}$ and $\mathrm{OIO}^{+}$

\begin{tabular}{|c|c|c|c|c|}
\hline & \multicolumn{2}{|c|}{$\mathrm{AE}$} & \multicolumn{2}{|c|}{$\mathrm{ECP}$} \\
\hline & $\mathrm{O}-\mathrm{I}$ & $\mathrm{O}-\mathrm{I}-\mathrm{O}$ & O-I & O-I-O \\
\hline \multicolumn{5}{|l|}{ OIO } \\
\hline $\mathrm{HF}$ & 1.758 & 109.1 & 1.741 & 109.6 \\
\hline MP2 & 1.810 & 111.1 & 1.797 & 111.1 \\
\hline B3LYP & 1.818 & 110.4 & 1.802 & 109.9 \\
\hline $\operatorname{CCSD}(\mathrm{T})$ & 1.816 & 110.6 & 1.804 & 110.8 \\
\hline $\operatorname{Exp}^{b}\left(\mathrm{r}_{0}\right)$ & 1.805 & 109.9 & 1.805 & 109.9 \\
\hline $\operatorname{Exp}^{b}\left(\mathrm{r}_{\mathrm{e}}\right)$ & 1.800 & 109.8 & 1.800 & 109.8 \\
\hline \multicolumn{5}{|l|}{$\mathrm{OIO}^{-}$} \\
\hline $\mathrm{HF}$ & 1.706 & 111.2 & 1.686 & 110.8 \\
\hline MP2 & 1.802 & 111.5 & 1.789 & 111.2 \\
\hline B3LYP & 1.772 & 110.1 & 1.753 & 110.2 \\
\hline $\operatorname{CcsD}(T)$ & 1.789 & 111.0 & 1.774 & 110.9 \\
\hline
\end{tabular}

"The bond length in $\AA$ and the bond angles in degrees. "From ref. 6 . very small changes that are less than $1.0^{\circ}$. This contraction of the bond length originates from the inclusion of scalar relativistic effects through the effective core potential for the I atom. The large change in the bond lengths. upon the inclusion of scalar relativistic effect. stresses that they are not negligible in molecular structures for compounds containing iodine or heavier atoms and thus. should be included in the calculations. at least. in the geometry optimization. The deviations of the optimized bond lengths from the experimental value are $-0.059 .-0.003 .0 .002$ and $0.004 \mathrm{~A}$ for HF. MP2. B3LYP, and CCSD(T), respectively: Although the MP2 bond length is slightly shorter than the experimental value and the bond lengths obtained at the B3LYP and CCSD(T) levels are slightly larger than the experimental value. all three bond lengths should be regarded as being equivalent

The $\mathrm{OIO}^{-}$turns out to possess $\mathrm{C}_{\hat{2} v}$ symmetry As $\mathrm{OIO}$ is ionized to form $\mathrm{OIO}^{+}$, the I-O bond lengths are optimized at all levels with both basis sets being shortened. The bond angle widens very slightly. The contraction in the bond length means that the $\mathrm{I}-\mathrm{O}$ bond in the $\mathrm{OIO}^{+}$ground state become stronger than the bond in the neutral species. The sizes of the bond contractions depend on the calculation method employed. The contractions in the bond lengths calculated with the $\mathrm{AE}$ basis are $0.053,0.008,0.046$ and $0.028 \mathrm{~A}$ for the HF. MP2. B3LYP and CCSD(T) methods. respectively. The bond contractions calculated with the ECP basis are very similar to those of the $\mathrm{AE}$ basis. The contraction in the MP2 bond length is exceptionally small compared to those obtained with the other methods. Thus. the relative order in the optimized bond lengths is changed from MP2 $<$ B3LYP $<$ CCSD(T) for the neutral species to B3LYP $<\operatorname{CCSD}(T)<$ MP2 for the ionized species. Since there is no experimental molecular structure for $\mathrm{OIO}^{+}$ available for comparison with the optimized structures. it is impossible to know which one among the MP2. B3LYP and $\operatorname{CCSD}(\mathrm{T})$ methods gives the best results for $\mathrm{OIO}^{+}$. But since the $\operatorname{CCSD}(\mathrm{T})$ method is the most soplisticated one for the inclusion of electron correlation and is expected to provide the most accurate calculated results. the $\operatorname{CCSD}(\mathrm{T})$ result can be regarded as the most accurate. At the $\operatorname{CCSD}(T) / E C P$ level. the I-O bond length contracted by $0.030 \AA$ and the bond angle widened by $0.1^{\circ}$ upon the removal of an electron from $\mathrm{OIO}$ to form $\mathrm{OIO}^{-}$.

The harmonic vibrational frequencies for both species calculated using the ECP basis set are listed in Table 2 along with the experimental ones for $\mathrm{OIO}{ }^{7.8}$ The first point to note is that although the geometries optimized with the MP2. B3LYP and CCSD(T) methods for OIO are very similar in quality: the harmonic vibrational frequencies calculated with the four methods are very different. The agreements between the calculated and experimental data improved in the order of $\mathrm{HF}<\mathrm{MP} 2<\mathrm{B} 3 \mathrm{LYP}<\mathrm{CCSD}(\mathrm{T})$. This pattern is in correlation with the pattern observed in the calculated vibrational frequencies for many molecules.

Consider the harmonic vibrational frequencies calculated for $\mathrm{OIO}^{+}$. Since there is no experimental data available for 
Table 2. The Calculated ${ }^{a}$ and Experimental Vibrational Frequencies $\left(\mathrm{cm}^{-1}\right)$ for $\mathrm{OIO}$ and $\mathrm{OIO}^{+}$

\begin{tabular}{lccccc}
\hline Mode & HF & MP2 & B3LYP & CCSD(T) & Exp. \\
\hline OIO & & & & & \\
OIO Bend & 333 & 274 & 271 & 267 & $250^{\circ}$ \\
IO Sym. str. & 911 & 841 & 787 & 775 & $768^{\circ}$ \\
IO Asym. str. & 961 & 873 & 803 & 802 & $800^{\circ}$ \\
OIO+ & & & & & \\
OIO Bend & 365 & 274 & 298 & 281 & \\
IO Sym. str. & 1052 & 810 & 876 & 792 & \\
IO Asym. str. & 1098 & 880 & 909 & 831 & \\
\hline
\end{tabular}

"The calculated vibrational frequencies are obtained using the ECP basis. ${ }^{5}$ From ref. $9 .{ }^{\circ}$ From ref. 8.

comparison with the calculated values. the harmonic vibrational frequencies calculated with the $\operatorname{CCSD}(\mathrm{T})$ method are chosen to be a reference for comparison with the other calculated values because the CCSD(T) method is known to be the most sophisticated one among the methods employed in the present study in the treatment of electron correlation. provides the best results for OIO and thus. is expected to give the best results for $\mathrm{OIO}^{+}$. The vibrational frequency for the $\mathrm{I}-\mathrm{O}$ asymmetric stretching is in the order of $\mathrm{HF}>\mathrm{B} 3 \mathrm{LYP}$ $>\mathrm{MP} 2>\mathrm{CCSD}(\mathrm{T})$. There is a switch in the positions of the MP2 and B3LYP results compared to the order observed in the calculated vibrational frequencies of OIO. This pattern is also observed for the I-O symmetric stretching and the O-I$\mathrm{O}$ bending mode. When the MP2 and B3LYP frequencies are compared with the $\operatorname{CCSD}(\mathrm{T})$ frequencies it is revealed that the quality of B3LYP frequencies for $\mathrm{OIO}^{+}$becomes worse than that for $\mathrm{OIO}$. This deterioration may be related to the known problem in the B3LYP results: the poor description of long range interaction in B3LYP functional. This problem seems to operate more intensively for the ionic compound such as $\mathrm{OIO}^{-}$. This phenomenon needs to be examined more closely.

Besides the vibrational frequencies calculated using the MP2 method the harmonic vibrational frequencies of the neutral species are shifted to the blue as the species is ionized. The shifts in the calculated frequencies obtained with the $\operatorname{CCSD}$ (T) method are 14. 17. and $28 \mathrm{~cm}^{-1}$ for the $\mathrm{O}-\mathrm{I}-\mathrm{O}$ bending. the $\mathrm{I}-\mathrm{O}$ symmetric stretching and the $\mathrm{I}-\mathrm{O}$ asymmetric stretching modes. respectively. These shifts indicate that the $\mathrm{IO}$ bonds are stronger in $\mathrm{OIO}^{-}$that in $\mathrm{OIO}$.
This is consistent with the change in bond lengths calculated for $\mathrm{OIO}^{+}$

The zero-point vibrational energy corrected adiabatic ionization potentials (AIPs) calculated for the OXO $(\mathrm{X}=\mathrm{Cl}$. $\mathrm{Br}$. and I) are listed in Table 3 along with the experimental AIP values of $\mathrm{OClO}$ and $\mathrm{OBrO}$. $^{18-21}$

Since the experimental value is available for $\mathrm{OClO}$ and $\mathrm{OBrO}$. consider the calculated AIPs for $\mathrm{OClO}$ and $\mathrm{OBrO}$ first. The AIPs calculated at the HF and B3LYP levels overestimate the experimental value of $\mathrm{OClO}$ by 22 and 44 $\mathrm{kJ} / \mathrm{mol}$. respectively: Those at the $\mathrm{MP} 2$ and $\operatorname{CCSD}(\mathrm{T})$ levels underestimate it by 44 and $7 \mathrm{~kJ} / \mathrm{mol}$, respectively. The inclusion of some core-valence correlation in the $\operatorname{CCSD}(\mathrm{T})$ result. that is. the change from the $\operatorname{CCSD}(\mathrm{T})$ to the CCSD (T.Full) method deteriorates the agreement between the calculated and experimental AIPs of $\mathrm{OClO}$ by $0.9 \mathrm{~kJ} / \mathrm{mol}$. The deviation of the CCSD(T.Full) result for $\mathrm{OC} 1 \mathrm{O}$ from the experimental value is only $-7.6 \mathrm{~kJ} / \mathrm{mol}$, showing an excellent agreement between the calculated and experimental values. The pattern observed among the AIPs of $\mathrm{OBrO}$ is similar to that for $\mathrm{OClO}$. The inclusion of some core-valence correlation. however. improves the calculated AIP by $0.7 \mathrm{~kJ} /$ mol. The influence of the basis set change from the $\mathrm{AE}$ to the ECP basis sets for the calculated AIP is negligible. The deviation of the average of AIPs calculated with the CCSD(T.Full) method for $\mathrm{OBrO}$ from the corresponding experimental value is $-9.8 \mathrm{~kJ} / \mathrm{mol}$.

The pattern observed in the calculated AIPs for OIO is similar to that for $\mathrm{OClO}$ and $\mathrm{OBrO}$. The AIPs of OIO calculated with the ECP basis set are smaller than the corresponding values obtained with the $\mathrm{AE}$ basis by about 4 $\mathrm{kJ} / \mathrm{mol}$. Only the MP2 result is an exception to this trend. The difference between the calculation results obtained with both basis sets can be attributed to the inclusion of the scalar relativistic effect through the effective core potential of the I atom. Since the core-valence correlation effects on the AIPs of $\mathrm{OXO}(\mathrm{X}=\mathrm{Cl}, \mathrm{Br}$, and $\mathrm{I})$ calculated at the $\mathrm{CCSD}(\mathrm{T}) / \mathrm{AE}$ level are less than $1.0 \mathrm{~kJ} / \mathrm{mol}$. and thus. the relativistic effect on the AIP of OIO is expected to be more important than the core-valence correlation missed in the ECP calculation for OIO, the AIP of OIO calculated with the ECP basis is expected to be better than the AIP calculated with the AE basis. There is no adiabatic ionization potential reported for OIO. The AIP calculated at the CCSD(T.Full)/ECP level is $936.7 \mathrm{~kJ} / \mathrm{mol}$. Since the error of this value is expected to be

Table 3. The Calculated and Experimental Adiabatic Ionization Potentials $(\mathrm{kJ} / \mathrm{mol})$ for $\mathrm{OXO}(\mathrm{X}=\mathrm{Cl}, \mathrm{Br}$, and I)

\begin{tabular}{|c|c|c|c|c|c|c|c|}
\hline Species & Basis Sets & $\mathrm{HF}$ & MP2 & BSIYP & $\operatorname{ccs} D(T)$ & $\operatorname{CCSD}(\mathrm{T}, \mathrm{Full})$ & Exp. \\
\hline $6 \mathrm{ClO}$ & $\mathrm{AE}$ & 1018.7 & 953.0 & 1040.7 & 9902 & 989.1 & $996.7 \pm 1.9^{4}$ \\
\hline \multirow[t]{3}{*}{$\mathrm{OBrO}$} & $\mathrm{AE}$ & 1042.0 & 935.3 & 1039.0 & 982.2 & 982.9 & $992.8 \pm 2.9^{b}$ \\
\hline & $\mathrm{ECP}$ & 1042.1 & 934.7 & 1036.4 & 982.5 & 983.0 & \\
\hline & Average & & 9350 & 1038.1 & 982.4 & 983.0 & \\
\hline \multirow[t]{3}{*}{$\mathrm{OIO}$} & $\mathrm{AE}$ & 999.1 & 898.6 & 988.7 & 940.3 & 940.1 & 945.4 \\
\hline & $\mathrm{ECP}$ & 996.6 & 889.9 & 985.3 & 936.2 & 936.7 & \\
\hline & Average & & 894.5 & 987.1 & 938.3 & 938.4 & \\
\hline
\end{tabular}

"From ref. 18 and $19 .{ }^{b}$ From ref. 20 and $21 .{ }^{\text {TT }}$ The estimated value in the present work. 
similar to the corresponding AIPs for $\mathrm{OClO}$ and $\mathrm{OBrO}$. the correct AIP of OIO can be estimated by correcting the average of deviations of the calculated values for $\mathrm{OClO}$ and $\mathrm{OBrO}$ from the corresponding experimental values. The estimated value is $945.4 \mathrm{~kJ} / \mathrm{mol}$ and its uncertainty is expected to be less than $5 \mathrm{~kJ} / \mathrm{mol}$.

Let us consider the pattern among AIPs of $\mathrm{OXO}(\mathrm{X}=\mathrm{Cl}$. $\mathrm{Br}$. and I). As X in OXO is changed from $\mathrm{Cl}$ to $\mathrm{Br}$. the AIP decreases $3.9 \mathrm{~kJ}$. If the same amount was changed when $\mathrm{X}=\mathrm{Br}$ is replaced with $\mathrm{X}=\mathrm{I}$, the AIP for OIO would be around $988 \mathrm{~kJ} / \mathrm{mol}$. This value however deviates from the estimated correct value by $43 \mathrm{~kJ} / \mathrm{mol}$. This phenomenon suggests that extrapolating the trend observed in the properties of compounds when the chlorine atom in the compounds is replaced with the bromine atom to the iodine compounds is not a good strategy for estimating the properties of iodine compounds.

\section{Summary}

Molecular geometries for the cationic and neutral species of $\mathrm{OXO}(\mathrm{X}=\mathrm{Cl}$. Br. and I) are optimized using the HF. MP2. B3LYP and CCSD(T) methods with two basis sets of triple zeta plus polarization quality: The single point calculations for these species are performed at the CCSD(T.Full) level. The harmonic vibrational frequencies for these species are calculated at the HF, MP2. B3LYP and CCSD(T) levels. The adiabatic ionization potential for OIO is calculated to be $936.7 \mathrm{~kJ} / \mathrm{mol}$ at the CCSD(T.Full) level and the correct value is estimated to be around $945.4 \mathrm{~kJ} / \mathrm{mol}$. This was obtained by correcting the calculated value with the average deviation of the calculated adiabatic ionization potentials for OClO and $\mathrm{OBrO}$ from the corresponding experimental data

Acknowledgments. This work was supported by the Kyungpook National University Research Fund. 1997.

\section{References}

1. Chase. M. W. J. Phys Chent. Ref. Data 1996. 25. 1297.

2. Wayne. R. P.: Poulet. G.: Biggs. P.: Burrows. J. P: Cos. R. A.: Crutzent. P. I.: Hayman. G. D.: Jenkins. M. E.: Le Bras. G.: Moortgat. G. K.; Platt, U.: Schindler, R. N. Amos. Eniron. 1995. 29.2677.

3. Cox. R. A.; Bloss, W. J.: Jones. R. L; Rowley, D. M. Geoplns. Res. Lett. 1999. 26. 1857.

4. Allan. B. J.: Plane. J. M. C.: MeFiggans. G. Geophys Res. Lett. 2001. 28. 1945 .

5. Hoffmann, T.: O'Dowd. C. Di; Seinfeld. J. H. Geophys. Res. Lett. 2001. 28,1949

6. Miller. C. E.: Cohen. E. A. J. Chem. Phus, 2003, 118. 6309.

7. Gilles. M. K.: Polak. M. L.: Lineberger. W. C. J. Chem. Phns. 1992. 96.8012 .

8. Maier. G.: Bothur. A. Chent. Ber-Recl, 1997. 130. 179.

9. Himmelmann. S: Orphal, J: Bovensmann. H.: Richter, A. Ladstătter-Weissenmaver, A.; Burrows, J. P. Chem. Plys. Lett. 1996. 251,330 .

10. Ashworth. S. H.: Allan. B. I.: Plane. J. M. C. Geophys. Res Lett. 2002. 29.65.

11. Bedjanian. Y.: Le Bras. G.: Poulet. G. J. Phws. Chem. A 1998. 102. 10501 .

12. Klemm. R. B.: Thorn. R. P., Jr; Stief. L. J.; Buckley; T. J.; Johnson. R. D. I. J. Phis. Chem A 2001, 105. 1638.

13. Frisch. M. T. et al. Gaussian 98. Revision A.7: Gaussian. Ine: Pittsburgh. PA. 1998

14. Curtiss. L. A.: MeGrath. M. P.: Blaudeau. J. P.: Davis. N. E.: Binning. Jr. R. C. Radom, L. J. Chem. Phys. 1995, 103.6104.

15. MoGrath. M. P.: Rowland. F. S. J. Plns. Chem. 1996. 100, 4815.

16. La John. L. A. Chritiansen. P. A. Ross, R. B; Atashroo. T: Ermler. W. C. J. Chem. Phys 1987, 87. 2812.

17. Lee. H. S. Ph. D. Thesis: KAIST. 2000.

18. Cornford. B.: Frost. D. C.: Herring. F. G.: McDowell. C. A. Chen. Phus. Lett. 1971. 10, 345.

19. Probst, M.: Hermansson, K.: Urban, J.: Mach, P.; Muigg. D.; Denifl. G.; Fiegele. T.: Mason. N. J.: Stamatovic. A.: Mark. T. D. J. Chent Phs 2002. 116.984

20. Thorn. R. P.. Tr.: Stief. L. J.: Buckley. T. T.: Tohn1sont. R. D.. III: Monks. P. S.: Klemm. R. B. J. Phs Chent A 1999. 103. 8384.

21. Dyke. J. M.: Gamblin. S. D.: Hooper. N.; Lee, E. P. F: Morris, A.: Mok. D. K. W: Chau, F. T. J. Chem. Plys. $2000.112,6262$. 